\title{
Sergio Ramírez, cultura política e o resgate do Sandino histórico
}

\author{
Sergio Ramírez, political culture and the rescue of the historic Sandino
}

Fred Maciel*

\begin{abstract}
Resumo: O artigo pretende apresentar algumas apropriações e elaborações realizadas desde a emergência do processo revolucionário nicaraguense, tendo como referência principal a figura de Augusto C. Sandino. Ao reconhecermos a existência de uma ampla cultura política sandinista, a atuação e escritos de Sergio Ramírez ganham destaque, especialmente na evocação de um Sandino histórico, com viés ético e humano. Assim, abordaremos o desenvolvimento de algumas dessas construções, bem como o desenrolar das mesmas, ressaltando a amplitude e diversidade do sandinismo enquanto importante força cultural e política da Nicarágua desde meados do século $\mathrm{XX}$.
\end{abstract}

Palavras-chave: Nicarágua, Sandino, sandinismo, Sergio Ramírez.

\begin{abstract}
The article intends to present some appropriations and elaborations made since the emergence of the Nicaraguan revolutionary process, having as main reference the figure of Augusto C. Sandino. Recognizing the existence of a wide Sandinista political culture, the work and writings of Sergio Ramírez gain prominence, especially in the evocation of a historical Sandino, with ethical and human bias. Thus, we will discuss the development of some of these constructions, as well as their progress, highlighting the breadth and diversity of Sandinismo as an important cultural and political force in Nicaragua since the mid- $20^{\text {th }}$ century.
\end{abstract}

Keywords: Nicaragua, Sandino, Sandinismo, Sergio Ramírez.

Recibido: 13 noviembre 2017

Aceptado: 27 diciembre 2017

\footnotetext{
* Brasileiro. Mestre e doutorando em História pela Universidade Estadual Paulista "Júlio de Mesquita Filho" (UNESP/campus Franca). O artigo é extraído da tese desenvolvida pelo autor, intitulada "Alterar la historia haciéndola, no solo contándola": intelectualidade e cultura política sandinista em Sergio Ramírez, com financiamento da CAPES. Contato: fredmaciel06@gmail.com
} 


\section{Introdução}

Após o fim do movimento de resistência armada contra a ingerência estadunidense na Nicarágua no início do século XX, cujo desfecho foi o assassinato de seu líder, a figura de Augusto C. Sandino consagrou-se como uma referência para iniciativas populares e ações de grupos associados à esquerda latino-americana. Especificamente no país centroamericano em questão, a influência da atuação do "general de hombres libres" foi decisiva na constituição da Frente Sandinista de Liberación Nacional (FSLN) enquanto movimento popular de massas no princípio da década de 1960, além de parâmetro de uma geração de jovens que então lutava contra o regime autoritário da família Somoza.

Em meio a essa geração, o atualmente renomado escritor Sergio Ramírez teve participação relevante no reavivamento da imagem e ideário de Sandino. Sua trajetória intelectual e política se entrelaçou desde a etapa como estudante universitário na Universidad de León, onde teve contato com as atividades de resistência ao somozismo e igualmente com o impacto direto das ações repressivas do governo vigente. A incorporação definitiva à luta antiditatorial dar-se-ia apenas em meados nos anos 1970, porém seu rol ativo foi progressivamente crescente e importante para a vitória insurrecional em 1979 e nos anos posteriores, culminando com o cargo de vice-presidente da República entre 1985 e 1990.

Como principal representante do Grupo de los Doce (grupo de civis destacados que apoiavam a FSLN e que contribuíram na aceitação dos sandinistas em âmbito local e internacional), como vice-presidente e respeito escritor, podemos considerar que Ramírez encarnou o símbolo de um novo sentido político pretendido por alguns membros da FSLN, de viés não apenas guerrilheiro/militarista e/ou orientado à via armada, buscando até mesmo uma imagem mais ampla e heterogênea em relação à participação de distintos setores sociais.

Nesse contexto, no desenrolar do vitorioso movimento insurrecional liderado pela FSLN, a análise da dimensão da influência de Sandino e sua representação pode contribuir na explicação do alcance de ditas ideias e igualmente de sua repercussão em meio não apenas aos militantes, mas à sociedade nicaraguense como um todo. Sabe-se que a FSLN tomou como pressuposto seguir o "legado" deixado por Sandino, envolto em um imaginário político e sociocultural que buscava reforçar uma identidade nacional própria. Desse modo, baseada nos princípios defendidos por Sandino, uma força aglutinadora constituiu-se e permaneceu como legado e como instrumento de mobilização (especialmente política) desde as últimas décadas do século XX. E justamente nesse ponto encontramos uma das especificidades de Ramírez: podemos considera-lo como um dos principais representantes e interlocutores de uma tradição política singular derivada de uma cultura política sandinista, de valoração ética e histórica, de modo que por meio de sua atuação e obra podemos não apenas verificar dita cultura política como também perceber seu impulso e desenvolvimento.

Ao reconhecermos a existência de uma ampla cultura política sandinista com diferentes tradições, englobando um conjunto de referências estabelecido com as ideias e 
pensamentos de Sandino revividos por uma geração de jovens radicalizados e descontentes com o somozismo, fazemos um esforço para compreender como uma interpretação comum do passado (e igualmente do presente) foi produzida e consolidada através do tempo, integrando-se ao imaginário e à memória coletiva de um grupo social atuante na vitoriosa insurreição de 1979, no governo da década de 1980 e na transição governamental.

Nesse sentido, levando em consideração o reavivamento da figura de Sandino e seu ideário, trataremos acerca de algumas apropriações e elaborações realizadas desde a emergência do processo revolucionário. Fundamentais na ampliação da representatividade simbólica e política de Sandino, tais recuperações passam, por exemplo, pelo resgate de um Sandino histórico realizado por Ramírez, focado no aspecto ético como principal herança. De maneira geral, os feitos históricos do período revolucionário foram refletidos em diferentes instâncias e de distintos modos na sociedade nicaraguense, com Sandino sendo ao mesmo tempo cancelado e preservado no mais alto nível da história local e regional.

A figura de Sergio Ramírez (bem como sua atuação) e o sandinismo foram - e considerando a persistência e ressignificações de tradições políticas e vertentes associadas a essa cultura política, ainda são - etapa relevante na história nicaraguense e latinoamericana; aprofundar em sua análise e na da conflitante Nicarágua mostra-se importante na compreensão da heterogênea e peculiar América Central.

\section{O resgate do Sandino "histórico"}

Redescoberto, estudado e utilizado como figura necessária por Carlos Fonseca (um dos líderes organizadores da Frente Sandinista e principal mentor intelectual da mesma) para aglutinar e desenvolver um ideal de luta, Sandino foi mobilizado de distintas maneiras com a progressiva ampliação do movimento liderado pela FSLN e seu consequente governo nos anos 1980. O que tentaremos demonstrar brevemente neste artigo é a percepção da premissa da elaboração de uma cultura política "primária" em torno da recuperação inicial da imagem e dos feitos de Augusto C. Sandino, envolta em uma geração de jovens e descontentes com o regime autoritário da família Somoza desde a passagem da década de 1950 para a de 1960, e que foi marcada pela criação da FSLN nos primeiros anos sessentistas. Principal articulador do reavivamento de Sandino, Fonseca deu o lastro "sandinista" à dita ampla cultura política. Após a morte do líder político em 1976, o desejo de pôr fim à ditadura e a posterior vitória insurrecional em 1979 e sua euforia e sentimento generalizado de esperança comprovaram ser suficientes para coesionar a sociedade, mesmo com a heterogeneidade de pensamentos e condutas políticas. O desenrolar dos fatos, culminando na derrota eleitoral em 1990, facilitou a dispersão das tendências coletivas de ação e reflexão, de modo que as já existentes culturas políticas da sociedade se revelassem e se distinguissem em meio à reordenação das forças sociopolíticas do país.

Circundado por esse contexto, e integrante da aludida geração de jovens de meados do século XX, Ramírez apresenta-se como exemplo e personagem ativo dessas e nessas culturas políticas e algumas de suas vertentes, especificamente de uma perspectiva orientada mais aos valores humanos e éticos do que políticos de Sandino. Conforme a ideia 
inicial de uma cultura política sandinista não homogênea e com tradições e representações diferentes em variados setores da sociedade, até mesmo por meio de elementos difusos impregnados no imaginário popular, o papel de Ramirez, enquanto intelectual, foi o de articular e dar sentido a vários desses vetores, produzindo uma nova intepretação sobre Sandino, capaz de revitalizar e reavivar a própria cultura política sandinista.

Sabe-se que Carlos Fonseca aprofundou sua análise e divulgação do pensamento sandinista na década de 1970. Para Fonseca, que insistiu na adesão do epíteto 'sandinista' ao movimento político-militar que emergira no decênio anterior, um dos caminhos era atrelar a ação guerrilheira à anterior luta e ideário de Sandino, recuperando-o como símbolo revolucionário aglutinador, convertido em um ícone da resistência armada perante uma situação de dominação no qual a população e a oposição ao regime somozista poderia se identificar. Possivelmente o primeiro a estudar sistematicamente e reviver o pensamento de Sandino, sendo fundamental no progressivo processo de "heroicização" do mesmo, a ascensão de Fonseca como líder central trouxe consigo um compromisso com um caráter essencialmente nicaraguense para o ambicionado projeto de "reconstrução" nacional, recaindo na constatação da importância do trabalho político. Nesse último, a FSLN seria apresentada como herdeira de uma tradição nacionalista e anti-imperialista e igualmente de um imaginário popular que remontava à atuação e figura de Sandino, possibilitando a consolidação da FSLN junto à população.

Nesse mesmo período, nos primeiros anos de dito decênio setentista, Sergio Ramírez já aportaria uma significativa e fundamental contribuição ao sandinismo: a publicação da primeira edição de seu trabalho de compilação dos escritos daquele que se tornaria o maior símbolo nacional nicaraguense, "El pensamiento vivo de Sandino". Publicada na Costa Rica em 1974, a obra trazia o primeiro esforço de Ramírez em reunir as principais formas de expressão do pensamento de Sandino: cartas, manifestos e documentos circulares às autoridades, comunicados e boletins de guerra, relatos autobiográficos, e entrevistas à imprensa.

$\mathrm{Na}$ nota explicativa dessa primeira edição, Ramírez apresentou alguns dos traços primordiais que assentariam tal cultura política e a recuperação do Sandino histórico:

No debe perderse la perspectiva de que cada una de las ideas expresadas por Sandino, está en alguna medida respaldada por su lucha; hay una correspondencia directa entre su pensamiento y su acción. Nada hay aquí que esté dicho gratuitamente y es esa misma correspondencia vital y visceral la que despoja a su lenguaje de toda contaminación retórica, hermoso lenguaje, como toda expresión de la verdad.

Son pues los escritos de un humilde artesano, recolector de café en su infancia; trabajador agrícola en lecherías y plantaciones; cortador de banano, ayudante de mecánica, empleado en cuadrillas de limpieza de calles; minero, tornero, despachador de gasolina, y general de un ejército del pueblo, que sostuvo con su brazo armado su verdad y su sacrificio ${ }^{1}$.

\footnotetext{
${ }^{1}$ Sergio Ramírez, El pensamiento vivo de Sandino, Managua, Editorial Nueva Nicaragua, 1984, 22.
} 
Como indicado, a preponderância é a de uma figura humana imersa em seu contexto, exemplo de valores e desprendimento. Ao passo que Carlos Fonseca apresentava o pensamento de Sandino, devidamente referenciado e documentado (em textos como "Sandino: Guerrillero Proletario" de 1971, por exemplo), associado à análise políticosocial, visando difundir a imagem do mesmo; Ramírez buscava organizar as composições escritas de Sandino, que até então apareciam de maneira dispersa e fragmentada em várias publicações, sem um sistemático rigor. $\mathrm{Na}$ apresentação da edição ampliada e final de " $E l$ pensamiento vivo de Sandino", de 1984, Ramírez valorizava esse seu esforço na circunstância do fortalecimento do movimento de oposição:

[...] tal intento tuvo la virtud de servir de pieza esencial en la lucha política e ideológica que en esa década decisiva para el triunfo revolucionario, debió librar el Frente Sandinista de Liberación Nacional, tanto dentro como fuera de Nicaragua: proyectar a Sandino y su pensamiento, era un objetivo de vital importancia ${ }^{2}$.

Portanto, quase concomitantemente a Fonseca, Ramírez empreendia seu empenho de preservar a devida ascensão da memória e histórico de Sandino, não esquecendo que, naquele momento, suas construções atendiam a propósitos intelectuais próprios e até mesmo partidários, sendo mais uma composição em meio a tantas outras que conformariam a pluralidade do sandinismo como cultura política e de seus (re)usos e aplicações. Todavia, as diferenças se evidenciavam na maneira de trabalhar com o uso do passado e da história nicaraguenses. Nesse sentido, mostra-se relevante e proveitoso para nossa análise aqui proposta a comparação entre dois escritos basilares, um de Fonseca e outro de Ramírez, elaborados em um intervalo temporal próximo (meados dos anos 1970) e exemplificadores dos caminhos da cultura política sandinista e de suas tradições que se sendimentavam. "Viva Sandino", extenso ensaio de Carlos Fonseca acerca de aspectos biográficos e político-ideológicos de Sandino, foi elaborado em 1974, mas publicado pela primeira vez somente em 1982, através do trabalho do então recém-criado Instituto de Estudio del Sandinismo (IES). Ramírez escreveu "El muchacho de Niquinohomo" entre 1973 e 1975, quando ainda estava em Berlim (atuando profissionalmente como bolsista junto a um programa de intercâmbio cultural-acadêmico), e nele analisa o contexto e as circunstâncias nicaraguenses e latino-americanas que rodearam a luta do guerrilheiro, além de relatar toda a vida do mesmo. Ambos os documentos são representativos para entendermos o processo de composição da figura de Augusto C. Sandino como referência e consequentemente base de uma cultura política.

Podemos considerar que a politização de Sandino é traço pronunciado no texto de Fonseca. A influência da Revolução Cubana se revelava uma orientação para o autor, repetidamente notada em "Viva Sandino". As primeiras páginas já vinculavam a rebeldia de Sandino à Conferência Tricontinental realizada em Cuba em 1966, às inaugurais Declarações de Havana e ao próprio Ernesto "Che" Guevara. Nas palavras de Fonseca:

\footnotetext{
${ }^{2}$ Ibid., 25.
} 
O lugar destacado de Sandino foi definido explicitamente por seu digno seguidor, Ernesto Che Guevara [...]. [D]urante longos anos, os próprios nicaraguenses ignoraram a si próprios. Talvez estejamos começando a recobrar a noção de nós mesmos, em consequência do início da nova batalha pela libertação cuja primeira vitória definitiva teve Cuba como cenário ${ }^{3}$.

A inserção de Sandino em uma tradição revolucionária continental visava também reforçar o entendimento de um caráter extremamente elitista e oligárquico das etapas de mudanças ocorridas na Nicarágua. De acordo com Fonseca, apesar das "rebeldias seculares", o atraso na chegada de opções e ideias marxistas e socialistas ao país (emergidas apenas após a experiência cubana) fez com que o único método de análise e resolução dos problemas nacionais fosse o liberal burguês ${ }^{4}$. Dessa forma, o resultado recorrente seria a ausência de uma mínima noção científica por parte dos setores mais pobres quanto à causa de suas dificuldades e adversidades.

Sergio Ramírez não faz nenhuma menção ao movimento cubano, optando por apresentar a luta sandinista original como circunscrita ao seu período e contexto. Ou seja, mais do que uma continuidade, a ação coletiva antiditatorial tomaria Sandino como exemplo e lição:

Por eso, preguntarse por qué Sandino no prosiguió su lucha hasta la conquista del poder, no es más que una proposición romántica; cumplió con su tarea, fue incluso al sacrificio para que su vida y sus acciones, las de sus hombres, pudieron ser recordadas como ejemplo en el futuro latinoamericano ${ }^{5}$.

Enquanto membro de uma geração, é evidente que Ramírez foi influenciado pela experiência cubana, assim como Fonseca foi um modelo intelectual para ele. Porém, sua preocupação parecia ser direcionada à composição de uma cultura nacional popular, um projeto de (re)construção da nação, com reduzidas ambições político-ideológicas em comparação com Fonseca.

Ambos reconheciam a motivação nacionalista e anti-imperialista de Sandino. A distinção está na abordagem da questão e suas motivações principais: para Fonseca, existia a identificação do líder guerrilheiro com ideais socialistas e revolucionários avançados; Ramírez, por sua vez, insistia na percepção do problema da nacionalidade, do desejo de rompimento da histórica dominação externa e oligárquica, fruto de um cenário vivido por ele de privações e pobrezas. Segundo Carlos Fonseca:

Naquele tempo havia trevas na mente da multidão popular; mas havia ira no coração dos rebeldes, traídos no Espino Negro. Sandino que, como peregrino em outras terras, pudera acolher em Cerro Azul o ideal proletário vindo de longe, foi o catalisador dessa

\footnotetext{
${ }^{3}$ Carlos Fonseca, "Viva Sandino", Mónica Baltodano e João Pedro Stedile (orgs.), Sandino: vida e obra, São Paulo, Expressão Popular, 2008, 26-27.

${ }^{4}$ Ibid., 42-43.

${ }^{5}$ Sergio Ramírez, “El muchacho de Niquinohomo”, Ramírez, op. cit., 1984, 64.
} 
ira. [...] Ao longo dos anos que sua luta durou, nota-se que a identificação com as ideias sociais limítrofes com o socialismo estiveram presentes em Sandino ${ }^{6}$. Sandino:

Por seu turno, Sergio Ramírez acentuava o senso de justiça e patriotismo de

El Partido Liberal, en armas contra el gobierno en la Costa Atlántica, peleaba una guerra que, según la mira de Sandino, debía ser también una guerra contra la intervención extranjera, y por eso buscó dar su propia batalla dentro de esas filas. [...] Sandino decidió aquella noche resistir, más con ánimo de sacrificarse como un ejemplo futuro, que con pretensiones de una victoria militar. Aquella decisión transformaría una guerra civil de facciones oligárquicas, en una larga guerra de liberación nacional; transformaría una guerra de soldados reclutados a la fuerza y de generales oportunistas, en una guerra en que generales y soldados serían todos pobres e hijos del pueblo, que andarían en harapos, que se llamarían unos a otros hermanos y cuya consigna escrita al pie de todos sus documentos oficiales, junto a un sello que representaba a un campesino decapitando con su machete a un soldado yanqui, sería la de Patria y Libertad; y aquella guerra convencional de montoneras, se transformaría en la primera guerra de guerrillas librada en el continente americano ${ }^{7}$.

Em vista disso, não seria um equívoco afirmar que Fonseca pretendia ir além de Sandino, definindo uma espécie de "contra-história" que iria transformar os nicaraguenses em sujeitos revolucionários, capazes de serem os portadores não apenas do antiimperialismo, mas da própria revolução socialista ${ }^{8}$. Por outro lado, a recuperação histórica de Sandino realizada por Ramírez, fundamentada quase que exclusivamente em seus escritos e biografia imersos no contexto do período, reiterava o lado humano do personagem, com seus valores éticos a favor da autonomia nacional nicaraguense. Vejamos:

Para muchos, ese general de los humildes, en cuyo rostro de muchacho se pintaban las huellas de las durezas de la lucha, había conquistado un derecho que los políticos entregados a los intereses de las compañías yanquis nunca habían tenido en cuenta: el de la nacionalidad, el de poder llamarse nicaragüenses, centroamericanos, latinoamericanos, el derecho de no ser colonos de un imperio?.

O interesse pelo poder talvez esclareça um pouco mais as diferenças de análise. Como buscamos demonstrar nas passagens citadas, Ramírez reafirmava o entendimento do papel de Sandino como luta pelos nicaraguenses, incluindo os setores liberais e

\footnotetext{
${ }^{6}$ Fonseca, op. cit., 58-82.

${ }^{7}$ Ramírez, op. cit., 1984, 45-47.

${ }^{8}$ Luciano Baracco, Nicaragua: the imagining of a nation. From Nineteenth-century Liberals to Twentiethcentury Sandinistas, New York, Algora Publishing, 2005, 78.

${ }^{9}$ Ramírez, op. cit., 1984, 60.
} 
conservadores $^{10}$. Fonseca avançou nesse ponto, enxergando a FSLN - como vanguarda e continuadora da luta sandinista - combatendo pelo povo contra todos os demais grupos políticos tradicionais. Em outras palavras, Fonseca traçava em seu horizonte a revolução político-social como objetivo, algo expandido da meta nacionalista de fim das ingerências estrangeiras no país delineada por Sandino, reiterada por Ramírez em termos de um novo projeto de nação, livre, justa e ética ${ }^{11}$.

Para concluir a comparação, é significativo como os autores encerram seus textos. Carlos Fonseca optou por retomar a influência cubana e a necessidade de condução das massas e de todo o processo revolucionário pela FSLN. Assim:

Uma coisa não é uma incógnita: a definitiva libertação nacional e social da Nicarágua não será alcançada se não houver uma organização armada e apoiada nas massas populares e orientada pelos mais avançados princípios revolucionários. As trevas que caíram sobre a Nicarágua a partir do assassinato de Sandino, no crime de 1934, prolongaram-se por um quarto de século. [...] Foi com o advento da Revolução Cubana de 1959 que o marxismo chegou ao rebelde espírito nicaraguense [...sendo] acolhido pela Frente Sandinista de Libertação Nacional que empreendeu de novo a trilha guerrilheira que vem crescendo na Nicarágua desde os últimos meses do ano de $1958^{12}$.

Em contrapartida, Sergio Ramírez frisou o pensamento oriundo da prática cotidiana, modelado pelas circunstâncias de luta. Nele, desprovido de interesses pessoais ou de poder, estariam os grandes exemplos de senso de justiça e nacionalidade:

La lucha de seis años del general Sandino en las montañas nicaragüenses, a la cabeza de un puñado de campesinos y obreros, debe verse como resultado histórico de siglos de dominación extranjera en su patria y de la constante entrega de los grupos dominantes a esos mismos poderes extranjeros. Aquellos hombres [...] probaron algo que hasta antes de la aparición de ese ejército del pueblo, había quedado escondido en los vericuetos de la historia latinoamericana: la hermosa posibilidad de que unos campesinos, con sus líderes propios, con sus tácticas forjadas al golpe de la marcha, con su doctrina surgida del proceso mismo de la lucha, organizaron una resistencia exitosa por la autonomía nacional ${ }^{13}$.

10 O traço "legitimista" de Sandino pode ser notado na aceitação e respeito ao governo de Juan Bautista Sacasa, eleito em 1933. Para Jorge Eduardo Arellano, Sandino acrediva lutar com um claro sentido legalista, tendo a constitucionalidade como elemento determinante e inerente ao seu conceito de soberania nacional. Ver: Jorge Eduardo Arellano, Guerrillero de nuestra América: Augusto C. Sandino (1895-1934), Managua, Hispamer, 2008, 36-37.

11 Seria equivocado dizer que Sandino não possuía nenhuma ambição de poder. Contudo, nos parece que a relação com a questão se direcionava mais à retirada das esferas decisórias daqueles que historicamente iam contra os interesses nacionais (a quem Sandino chamava de "vendepatrias") e o estabelecimento de uma forma de poder de caráter popular e concernente a todos os setores nicaraguenses, não necessariamente com sua pessoa como mandatário.

12 Fonseca, op. cit., 101.

${ }^{13}$ Ramírez, op. cit., 1984, 63. 
Desse modo, se quisermos pensar em uma cultura política sandinista com a qual Ramírez dialogou e foi ao mesmo tempo difusor, devemos atrelar substancialmente com essa restauração de um Sandino histórico, portador de valores éticos puros e justos. A partir dessa consideração, o fazer-se intelectual e político de Ramírez - seja antes, durante e/ou após o regime liderado pela FSLN - torna-se mais coeso e apreensível, tal como pontuaremos algumas observações a continuação.

Diferente dos considerados "ideólogos" da revolução nicaraguense (Fonseca, Humberto Ortega, Tomás Borge, Jaime Wheelock), Ramírez pareceu não querer transformar radicalmente a herança de Sandino. O resgate do corpus deixado por ele foi o primeiro e imprescindível ato a favor da sistematização de uma visão patriótica, mas também de uma proposta ética, cultural e social. A remodelação da situação de dominação (a intervenção armada dos marines no início do século XX e o regime autoritário familiar na segunda metade do mesmo século) fortaleceu a convicção da luta contra uma realidade de exclusão, a ser pautada em uma postura moral íntegra; justa e rigorosamente, a crítica posterior de Ramírez e outros nomes e setores às mudanças na FSLN e no uso retórico do sandinismo. Ou seja, as elaborações e projetos de Ramírez tinham suas motivações próprias. Imerso em uma projeção histórica de acordos interelitistas e do uso do Estado como fruto desses pactos, alinhar uma proposta ética e historicizada mostrava-se uma missão para si mesmo na condição de intelectual comprometido e que "fala" pelos subalternos. A consciência do que fora a ditadura e a esperança de superar esse passado atuava como uma força centrífuga que Ramírez buscava envolver em diálogo com o rearranjo do país. Uma perspectiva que sempre alentou seus esforços, adequando-se às situações e transições ocorridas, tal como uma marca de fidelidade por seus princípios.

Essa perspectiva sobre o uso da imagem de Sandino e mesmo sobre a condução política daquele momento em questão pode ser encontrada em outros escritos de Ramírez. Um, em especial, foi tão amplamente divulgado e reproduzido quanto "El muchacho de Niquinohomo" e os tomos de "El pensamento vivo de Sandino": trata-se de uma conferência intitulada "Sandino: clase e ideología", proferida por Ramírez a jovens e militantes em maio de 1980 na Escuela de Cuadros del Frente Sandinista de Liberación Nacional "Ricardo Morales Avilés", fundada em 1979. O trabalho aprofunda a análise do pensamento e das razões de Sandino já expostas em "El muchacho...", dessa vez com a apropriação dando uma sustentação mais nítida ao discurso revolucionário, uma vez que naquele momento já era um dos membros da Junta de Governo que conduzia o país.

De maneira didática, Ramírez apresentou o contexto social da luta sandinista, remetendo ao fim do século XIX nicaraguense com a revolução liberal de 1893 e a incorporação tardia à divisão internacional do trabalho; e o posterior retorno ao poder da oligarquia pecuarista no início do século XX, com apoio direto dos Estados Unidos, de modo a facilitar a ocupação desses últimos baseada em uma justificativa ideológica condicionada a agradecer e a julgar a interferência estadunidense como salvadora e civilizadora ${ }^{14}$. Segundo Ramírez, a submissão dos grupos oligárquicos, a debilidade dos setores médios e o não desenvolvimento de uma burguesia local confluíram para a

\footnotetext{
${ }^{14}$ Sergio Ramírez, "Sandino, classe e ideologia”, Baltodano e Stedile (orgs.), op. cit., 107.
} 
inexistência da nacionalidade como vértice de um espectro ideológico, fundamentando o estigma "vendepatria": "E a complacência e cumplicidade dos grupos dominantes locais leva-os a encampar esse projeto ideológico [afã de demonstrar a excelência econômica que a dominação acarretava, superioridade racial estadunidense], buscando refleti-lo em todos os aspectos da vida nacional ${ }^{15}$ ".

O problema da nacionalidade e a privação de uma cultura e ideologia próprias estariam, então, entre os principais impulsores da luta de Sandino, que, pela primeira vez, introduzia a variável popular em meio à tradição de guerras de facções de caudilhos e proprietários de terras:

A luta de Sandino contra os yankees não foi a luta da burguesia nacional contra a ocupação militar estadunidense, mas a luta do povo, como classe, que assumia em armas a defesa da nação e da nacionalidade [...]. E, devido à composição popular do exército libertador, à projeção ideológica que no fundo tem essa luta, ao momento histórico em que está inscrita, possui um caráter de classe, independente de que em um contexto teórico receba ou não orientações de caráter classista. [...] Mas na práxis, no combate diário, na expressão ideológica desse combate, a luta de Sandino foi uma luta de caráter nitidamente popular ${ }^{16}$.

O que Ramírez buscava projetar era o reconhecimento de Sandino como profundo entendedor da realidade nicaraguense, visto que o mesmo compreendeu a aliança entre as oligarquias e a dominação estrangeira, um pacto antipopular que resultava na motivação antioligárquica e anti-imperialista de sua luta de resistência. Isto é, para o intelectual, em caráter de sacrifício, Sandino encabeçou um reduzido setor popular que soube interpretar os interesses nacionais como uma vanguarda histórica ${ }^{17}$. Isso implica um pequeno avanço analítico de Ramírez, deixando mais claro que o movimento sandinista foi sim produto de um contexto específico, mas não foi estático ou estava confinado como um fenômeno histórico do fim dos anos 1920 e início dos 1930; possuindo uma dinâmica no panorama contemporâneo:

Só podemos ler Sandino no contexto dessa dinâmica, visto que a guerra contra a ocupação estrangeira não terminou em 1933, mas continuou em 1933, e que a luta de Sandino não foi mais do que uma parte de toda essa guerra, que desembocou na vitória de 19 de julho de $1979^{18}$.

É interessante notar como os primeiros anos de governo na década de 1980 remodelaram sensivelmente o discurso de Ramírez, tornando-o mais próximo do teor utilizado por Carlos Fonseca. Enquanto membro importante da FSLN e referência como figura intelectual do período, além da inegável euforia pós-vitória insurrecional, é

\footnotetext{
15 Ibid., 111.

${ }^{16}$ Ramírez, op. cit., 2008, 113-114.

17 Ibid., 115.

${ }^{18}$ Ibid., 116.
} 
compreensível o crescimento das referências à Frente Sandinista em seus discursos e escritos.

Nesse sentido, em "Sandino: clase e ideología" o tom "partidário" se alia aos seus recorrentes enunciados éticos e de reconstrução da nação. Os elementos fundamentais de Sandino foram apresentados de maneira mais propositiva, anteferindo as ideias de soberania, autonomia e nacionalidade às de anti-imperialismo e antioligarquismo, por exemplo; apresentando-as como conceitos populares e de classe ${ }^{19}$. Emaranhar-se por essas ideias e pela dinâmica do pensamento de Sandino era necessário para reconhecer a atualidade das suas reivindicações e ações, em uma raiz popular comum:

Se analisássemos essa concepção da luta com um critério imediatista, iríamos considerá-la um fracasso. Mas se tomarmos a epopeia de Sandino como a base de uma luta histórica, que sequer começa ali, mas que tem antecedentes em todo nosso passado de resistência popular, então, verdadeiramente, ela adquire uma dimensão de eixo na história de libertação da Nicarágua: uma luta que vai desembocar mais tarde na Frente Sandinista ${ }^{20}$.

"Bajo la sombra de Sandino", sob seu amparo e sob o controle daqueles que elaboraram essa lembrança, tratava-se de exprimir uma dinâmica histórica (com matriz na luta nas montanhas segovianas) escorada em um nacionalismo militante e armado e, sobretudo, em um caráter anti-imperialista.

Em uma perspectiva mais teórica é interessante que retomemos o historiador francês Serge Berstein ${ }^{21}$, quando este pontuou que os nascimentos das culturas políticas correspondem às respostas dadas a uma sociedade frente aos grandes problemas e crises, com fundamento suficiente para que se inscrevam na duração e atravessem gerações. Seguindo tal concepção, a cultura política sandinista difundida por Ramírez, e com a qual também dialoga, atende a esse critério ao proclamar-se como solução à situação de dominação e marginalização dos setores populares. Para aquele período, logo após a ascensão revolucionária ao poder, a idealização de uma leitura comum do passado e de uma projeção no futuro vivida em conjunto passava necessariamente pelo anti-imperialismo como aspecto de união.

Consideramos os traços éticos e históricos mais relevantes na apreensão de Ramírez em tal cultura política, porém, é inegável que o componente ideológico associado às noções anti-imperialistas precisava ser usado, a fim de enraizar o projeto político da FSLN; já que seria através e dentro desse projeto que Ramírez poderia propagar suas propostas intelectuais. Em uma palestra ministrada em um evento ${ }^{22}$ sobre a herança de Sandino

\footnotetext{
${ }^{19}$ Ibid., 117.

${ }^{20}$ Ibid., 123.

21 Serge Berstein, “A cultura política”, Jean-Pierre Rioux e Jean-François Sirinelli, Para uma História Cultural, Lisboa, Estampa, 1998.

22 Ocorrido entre os dias 27 e 31 de agosto de 1979, o "Seminario Político Educativo sobre Sandino, el Sandinismo y sus proyecciones en la determinación del Proceso Educativo" teve como temática central o ideário político-social de Sandino, com participações de lideranças revolucionárias e intelectuais.
} 
realizado na Universidad Centroamericana (UCA), pouco após a queda do somozismo, Ramírez ressaltou a constante anti-imperialista no histórico das lutas de libertação na Nicarágua, de maneira a vincular os esforços de Sandino diretamente às condições de injustiça vivenciadas no país. Mais uma vez, a consideração do contexto social e políticoeconômico exibia-se como ponto vital na análise do intelectual.

Naquela oportunidade, um trecho de sua fala retrata o teor da elaboração de uma premissa básica para a vertente da cultura política que estamos tratando, conectando o fundamento ideológico aos valores éticos e históricos de sua ação:

Muchos historiadores y politólogos se preguntan si realmente existió un pensamiento de Sandino, un pensamiento sandinista. La respuesta es claramente, sí. La lucha sandinista de 7 años en las Segovias y lo que significó como consecuencia histórica en Nicaragua, tuvo una expresión ideológica; lo que habría que determinar es cuáles son los parámetros de esa expresión ideológica. [...] Lo que siempre he querido demostrar alrededor del pensamiento de Sandino es la carga de verdad, la carga de praxis que tiene el pensamiento sandinista, la cual le da un contexto ideológico ${ }^{23}$.

Com características plurais e multifacetadas, as culturas políticas podem também ser percebidas como fenômenos dinâmicos, resultante de experiências e expectativas dos indivíduos e grupos em ação. Ademais, enquanto leituras do passado que conotam positiva ou negativamente períodos, personagens, eventos e textos referenciais, é viável o vínculo com a cultura histórica, a relação que uma sociedade mantém com seu passado. Nesse sentido, a noção de cultura política implicaria a identificação de uma espécie de um conjunto de referenciais constituídos e formalizados em um grupo social ou a partir de uma tradição política; ou seja, um fator de agregação social, uma visão comum da vida em sociedade.

É nesse entendimento que a figura de Sandino foi retomada por Ramírez, conforme uma referência e exemplo de valores e de atitudes humanas que historicamente podem ser reagrupadas. Isto posto:

Sandino no es un individuo, Sandino no es un caudillo en el sentido tradicional, no es una figura arbitraria de la historia nicaragüense, sino que Sandino resume siglos de explotación, de dominación colonial, de dominación extranjera en Nicaragua, de injusticias. Sandino representa el pensamiento de miles de campesinos, de miles de trabajadores humillados, explotados de esta tierra, que por primera vez pueden organizar en un contexto lúcido en Nicaragua, sus demandas, las demandas por las tierras, las demandas por las justicias, que a su vez tienen que ver mucho por la soberanía nacional. Es decir, no existe en el contexto sandinista soberanía nacional sin

23 Sergio Ramírez, "El ideario político-social de Sandino y el sandinismo. Análisis histórico-social del movimiento sandinista desde el origen hasta la maduración", Encuentro: Revista Académica de la Universidad Centroamericana, n. 15, 1980, 10. 
justicia social, son dos cosas que están íntimamente ligadas, o mejor dicho, son dos cosas que son la misma $\operatorname{cosa}^{24}$.

Desse diálogo entre passado e presente o processo instituinte de uma nova sociedade poderia se tornar legível, é dele que poderia surgir uma compreensão sintética do mundo e especificamente de uma "nova Nicarágua" sandinista.

O reconhecimento de Ramírez como difusor dessa ampla cultura política sandinista, só que permeada pelos valores éticos e históricos de Sandino, bem como baseada em um projeto de (re)construção da nação, carrega consigo a autofiguração como intelectual responsável por conduzir os setores subalternos da sociedade. Atuando como escritor preocupado em narrar a nação, em descrever figuras aglutinantes e em expressar o caráter cultural do país e da região, Ramírez percebia Sandino como fundamental para sedimentar e conjugar os novos ideais culturais e sociopolíticos:

Porque no se ha profundizado verdaderamente en el pensamiento de Sandino, yo creo que una de las tareas principales de la revolución va a ser que cada día que pase, se pueda sistematizar el estudio del pensamiento de Sandino. Tendrá que haber en las universidades cátedras de estudios sandinistas; tendrá que haber seminarios de estudios sandinistas permanentes en Nicaragua. Cada día que pase, esto se volverá más importante, no sólo para explicar el pensamiento en sí de Sandino en sus cartas, proclamas, discursos, sino la influencia directa e indirecta que Sandino representa en el pensamiento revolucionario a partir de entonces; y esto es muy importante, es decir, ninguno de los ideólogos del movimiento sandinista en Nicaragua, a partir de entonces, puede aplicarse a sí este pensamiento sandinista original. [...] Ningún revolucionario nicaragüense puede explicar su pensamiento sin estos orígenes del pensamiento sandinista. Es decir que toda la rueda de la revolución en Nicaragua, gira impulsada por este motor que es el pensamiento sandinista $[\ldots]^{25}$.

O destaque na citação acima antecipa uma das principais críticas às transformações na FSLN e na condução política de Daniel Ortega ocorridas desde os últimos anos do século XX, relacionando-se com as ressignificações e reapropriações da cultura política sandinista e de suas diferentes tradições. Nesse caso, cisões internas, discordâncias na interpretação do poder e da noção de política, além da própria ação do tempo, compuseram contextos específicos, alterando $\mathrm{o}$ antes positivo e empolgado ambiente social nicaraguense. A despeito disso, não podemos refutar a presença de uma ampla cultura política sandinista nos anos 1980 (para além de orientações e vertentes mais específicas e direcionadas, como a conduzida por Ortega e a direção da FSLN ou a trabalhada por Ramírez). Dessa forma, podemos refletir como, num dado momento histórico, uma cultura política constitui um todo homogêneo cujos elementos são interdependentes e cuja apreensão permite perceber o sentido dos acontecimentos em sua complexidade, graças à visão de mundo das pessoas que compartilham essa cultura.

\footnotetext{
${ }^{24}$ Ibid., 14.

25 Ibid., 15-16. O grifo é nosso.
} 


\section{Cultura política sandinista}

Tal qual apresentamos, uma abrangente cultura política assentada na imagem referencial de Sandino cobria praticamente todos os setores sociais ligados direta ou indiretamente ao novo governo instaurado (incluindo não militantes), permitindo que interpretações particulares e/ou direcionamentos singulares (individuais ou coletivos) gerassem novas tradições a partir desta, à semelhança do que expomos ao redor de Ramírez.

Neste sentido, para o então membro da Junta de Governo, o pensamento de Sandino permanecia contemporâneo, suas ideias básicas eram o sustentáculo para o desenvolvimento de novas propostas a favor da soberania e nacionalidade nicaraguenses:

No podemos decir que todas las ideas que mueven el proyecto revolucionario sandinista estaban en la mente de Sandino, que estaban en el proyecto de Sandino. Tenemos que pensar que se trata de otra época, de circunstancias con matices diferentes; si bien es cierto que la intervención es la misma, que la contradicción es la misma y que el enemigo es el mismo, el desarrollo de las fuerzas productivas en el país es diferente, tiene otra calidad; el desarrollo de las fuerzas sociales en Nicaragua también está en otra etapa ${ }^{26}$.

Ao menos para Ramírez, a possibilidade de sair de um antigo debate teórico sobre a conduta da esquerda latino-americana quando estava no poder marcava o sandinismo como um modelo de concepções próprias, após um longo período de frustrações: "[...] y la novedad en Nicaragua, y la esperanza, era que se rompían los viejos moldes para dar paso a un proyecto novedoso, y por tanto, diferente ${ }^{27}$." Contudo, toda essa potencialidade inovadora revelar-se-ia, ao fim, frustrada.

A análise dos escritos e discursos de Ramírez no período de auge do movimento sandinista (últimos períodos dos anos 1970 e primeira metade da década seguinte) retrata a relação de duas constantes: a profissão de escritor e a experiência militante revolucionária que o definem a si mesmo. De acordo com Diana Irma Moro ${ }^{28}$, tal amalgama sinaliza também a presença constante de um "eu" autoral que argumenta e fala de si mesmo, com discursos que monumentalizam atos e autofigurações como um escritor que participou heroicamente da etapa revolucionária.

O teor das sentenças de Ramírez apresentadas nas páginas antecedentes expõe um intelectual defensor da cultura política sandinista com um viés ético e humano, mas que,

\footnotetext{
26 Sergio Ramírez, "Vigencia del pensamiento sandinista. Conferencia pronunciada por el doctor Sergio Ramírez Mercado, miembro de la Junta de Gobierno de Reconstrucción Nacional, en el auditorio del diario Barricada. Managua, 3 de febrero de 1983”, Instituto de Estudio del Sandinismo, El sandinismo: documentos básicos, Managua, Editorial Nueva Nicaragua, 1983, 25.

${ }^{27}$ Sergio Ramírez, "Un sandinismo en el que creer”, Sergio Ramírez, Oficios compartidos. Un sandinismo en el que creer, Poitiers, França, Centre de Recherches Latino-Américaines-Archivos, 2000.

${ }^{28}$ Diana Irma Moro, "Sergio Ramírez: ensayo y autofiguración”, Revista Pilquen, Sección Ciencias Sociales, XVI, 17:01, 2014, 07.
} 
por sua posição e vivência, abarcava inevitavelmente uma carga ideológica que o aproximava naquele momento ao conteúdo classista e "politizado" de Carlos Fonseca e da liderança da FSLN. Ademais, a formação universitária de Ramírez coincide com o ambiente de confiança pós-Revolução Cubana e com a abundante elaboração de teoria social, econômica e política produzida desde fins dos 1950 em diante ${ }^{29}$.

O que pretendemos pontuar é que essa ligação não interfere ou impossibilita a reflexão mais histórica e moral de Ramírez, mantendo sua interação com a cultura política sandinista indicada mesmo após a derrocada do regime liderado pela FSLN, e até mesmo tornando-se um dos principais críticos da gestão do processo e do que se estava fazendo consequentemente.

Nessa lógica, as obras e ensaios de Ramírez sobre a Revolução Sandinista formam parte essencial na assimilação da cultura política sandinista aqui tratada. Produzidas e publicadas quase em sua totalidade nos anos 1980, veiculavam discursos e relatos do autor apegados à ambição de uma independência cultural e de um nacionalismo comprometido, com estratégias ideológicas de criar e fortalecer uma imagem positiva do país e do processo revolucionário. "El alba de oro", de 1983, por exemplo, reúne textos que constituem documentos da construção política e ideológica da situação revolucionária e de seu próprio crescimento como intelectual ${ }^{30}$. Na introdução do livro, Ramírez expôs um toque comum à maioria de suas publicações do período:

Este libro, sin embargo, es el libro de un escritor, pero concebido de una manera diferente: como las reflexiones e impresiones de un dirigente político sobre un proceso histórico crucial para la América Latina, como es la revolución popular sandinista, un proceso que todos los días suma nuevas experiencias, afina sus virtudes y corrige sobre la marcha sus errores. [...] Es el testimonio diario, sin pretensiones, de un intelectual en su aprendizaje constante con la revolución y con las masas que dirigidas por el Frente Sandinista, la llevan adelante ${ }^{31}$.

É interessante notar que seu compromisso com a dignidade humana e com a soberania nacional (bases da visão da cultura política sandinista que difunde e dialoga) está presente tanto em seus ensaios e discursos quanto nas obras literárias, exteriorizando uma função ideológica do narrador, que busca recursos expressivos mais idôneos para descrever (ou ficcionalizar nos romances) a realidade histórica e política nicaraguense. Registrar e documentar sua versão das experiências passadas, garantir a memória e ratificar suas ideias de nação, esses pareceram ser objetivos de Ramírez ao fragmentar a realidade trabalhando com dicotomias (passado/presente, ditadura/sandinismo, atraso/progresso), de modo que

\footnotetext{
${ }^{29}$ Ibid., 02.

${ }^{30}$ Diana Irma Moro, La narrativa de Sergio Ramírez y las significaciones de la figura de Rubén Darío en la constitución de la literatura nicaragüense, Tese de Doutorado em Letras, Universidad Nacional de La Plata, Facultad de Humanidades y Ciencias de la Educación, 2013, 192.

31 Sergio Ramírez, El alba de oro: la historia viva de Nicaragua, México, D.F., Siglo Veintiuno Editores, $1985,09$.
} 
não apenas o lado político, mas a cultura e a literatura constituíssem formas de representação do panorama sócio-histórico.

Defendemos a ideia de que o período pós-derrota eleitoral da FSLN foi o de confirmação de Ramírez como gestor e difusor da cultura política sandinista, notadamente de uma tradição específica oriunda da mesma. Para tanto, suas ações e decisões foram tão importantes quanto seus escritos e discursos. Assim, abordaremos algumas realizações do mesmo após o intervalo como vice-presidente e em meio às mudanças no contexto nicaraguense.

Mais do que a transição de governo, foram as alterações no seio do bloco sandinista que repercutiram de maneira intensa em Sergio Ramírez. Sabe-se que as diferenças de pensamento já existiam no interior da FSLN desde antes da vitória insurrecional de 1979, e que persistiram nos 1980 sobrepostas por um desejo comum de mudança. O desfecho das votações de fevereiro de 1990 serviu com uma espécie de pretexto para que tais discordâncias voltassem à tona. Nos anos ulteriores, Ramírez defenderia a premissa de que a queda sandinista se deu em grande parte pelo fim da ideia de projeto coletivo, com o isolamento da direção da Frente Sandinista em relação à população, principal motor de ascensão da FSLN e igualmente do regime da mesma. Ao fim, a democracia tornou-se o principal produto da etapa revolucionária. O reconhecimento da derrota em 1990 e a abertura da possibilidade de um caminho político mais democrático (via processo eleitoral) talvez tenham sido legados mais visíveis do que as tentativas de promoção de desenvolvimento e riqueza ao menos amparados. Nas palavras de Ramírez:

Hay un abismo que empieza a ensancharse entre el idealismo revolucionario de la lucha, y el proyecto político, ya en el poder. Lo que pudo haber sido la nueva calidad de la izquierda en el poder, se perdió en los vericuetos de una cultura política tradicional y en muchos sentidos bastante elemental. Quienes habían llevado al sandinismo al poder por la fuerza de las armas, y detentaban el poder real, eran hijos de los manuales, donde los modelos políticos estaban predeterminados, y simplificados. Y no deja de ser éste un asunto cultural; los modelos reales eran Cuba y el campo soviético, aún en sus rituales. Copiarlos, o imitarlos, era más sencillo que inventar otros distintos dentro de la amplia gama de posibilidades que una revolución abre para crear. Y ese potencial creador, resultó frustrado ${ }^{32}$.

Para ele, a questão da manutenção do consenso foi deixada de lado pelos mandatários do país ("se impusieron con más fuerza la arrogancia y los prejuicios

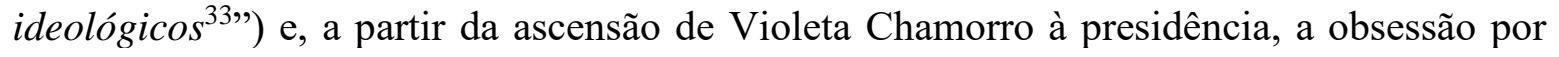
retornar ao poder transformou os direcionamentos da FSLN, fazendo da imagem de Sandino apenas um mero recurso retórico.

A derrota eleitoral da FSLN em fevereiro de 1990 não pôs fim ao sandinismo enquanto ideia de uma nação independente, democrática e livre de ingerências externas inspirada no pensamento e ações de Augusto C. Sandino, mas sim ao projeto político-social

\footnotetext{
${ }^{32}$ Ramírez, op. cit., 2000.

${ }^{33}$ Idem.
} 
de uma organização sandinista (ainda que derivada de uma autoadjetivação) que deteve as esferas de decisórias de poder por cerca de uma década.

Sob a perspectiva da FSLN, o governo Chamorro foi uma etapa interna de desorientação e debate, dando início ao processo de discussões entre grupos e linhas de orientação, muitas vezes com teores pessoais e violentos. A controvérsia em torno das reformas constitucionais que pretendiam pôr fim à fusão Estado-partido aplicada pelos sandinistas na década anterior, bem como eliminar a corrupção administrativa e o encobrimento de poderosos pode ser considerada um dos pontos altos da então latente cisão na FSLN. Porém, antes mesmo de tais debates em meados dos anos 1990, as diferenças e a decomposição interna já eram visíveis. Ainda em 1990, o primeiro congresso da Frente Sandinista foi realizado para tratar dos motivos da derrota eleitoral, assim como da necessidade de recomposição organizativa e discursiva, e do estabelecimento de uma estratégia agora como força de oposição ${ }^{34}$.

A acelerada transformação de uma organização controladora de todos os aparatos estatais a um partido "normal" trouxe consigo distintas visões da condução dessa etapa. Por um lado, uma corrente renovadora, pragmática, representada principalmente por membros em cargos de representação e institucionais (como deputados, por exemplo), defensores de uma transformação que estabelecesse uma formação política ampla, que dialogasse com diferentes setores sociais e políticos, buscando um consenso. Os então líderes parlamentários Sergio Ramírez e Dora María Téllez, além de Henry Ruiz e Luis Carrión (dois dos nove comandantes da Direção Nacional durante o governo da FSLN) encabeçavam dita corrente, depois nomeada como "Por un sandinismo que vuelva a las mayorías", em referência a um documento homônimo publicado por esse grupo em fevereiro de 1994.

A outra linha, conhecida como "Izquierda Democrática", possuía características mais ortodoxas, principistas, decidida a manter as estruturas, estratégias e estilo político, ou seja, uma oposição beligerante e combativa, buscando manter o que consideravam uma vocação revolucionária e vanguardista. Liderados por outros membros históricos como Daniel Ortega e Tomás Borge, basicamente possuíam o controle das principais instâncias do aparato partidário e das bases organizadas.

O encargo de adaptar-se a um entorno adverso e impensável a partir de 1990 favoreceu a implementação de medidas teoricamente mais democráticas no interior da FSLN enquanto partido. O estatuto aprovado em 1991 elucidava o respeito à Constituição, definia a supremacia de um Congresso Nacional e de uma Assembleia Sandinista sobre a Direção Nacional (posteriormente dissolvida), além da autonomia orgânica de movimentos e organizações próximas à FSLN, inaugurando marcos realmente partidários.

Contudo, a ferrenha disputa pela manutenção de espaços e influências nucleares, especialmente por parte da linha comandada por Daniel Ortega, parece indicar que, mais do que reflexões acerca de valores e estratégias político-institucionais que beneficiariam a

\footnotetext{
34 Salvador Martí i Puig, "Mutaciones orgánicas, adaptación y desinstitucionalización partidaria: el caso del Frente Sandinista de Liberación Nacional (FSLN), 1980-2006”, Revista de Estudios Políticos (nueva época), n. 143, 2009, 112.
} 
democracia nicaraguense, foi uma lógica crua de preservação de poder que permeou as cisões e mutações da Frente Sandinista. A esse respeito, afirmou o cientista político Nayar López Castellanos:

El debate interno en el Frente, planteado inicialmente para mejorar la organización bajo una lógica democrática, terminó con una división que solo reflejó el peso de los intereses individuales y de grupo frente a las necesidades políticas que la sociedad nicaragüense, sobre todo aquella de filiación sandinista, esperaba de esta fuerza en el contexto de la ola neoliberal que pulverizó toda prioridad social para Nicaragua en un corto tiempo ${ }^{35}$.

Os rompimentos no eixo partidário causaram saídas de antigos líderes e personagens relevantes no governo revolucionário, sendo a criação do Movimiento Renovador Sandinista (MRS) em 1995 um marco na tendência de condução personalista da FSLN. Reunindo, basicamente, a militância sandinista associada aos âmbitos intelectual, acadêmico e cultural-artístico, e sob a liderança de Sergio Ramírez, o MRS selou a ruptura do sandinismo como agrupação política. O considerável apelo ideológico, mas com resultados pouco numerosos nos pleitos seguintes demonstraram que o MRS era uma força

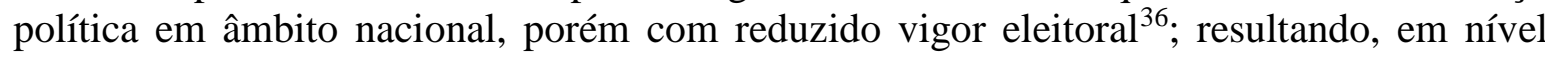
partidário, na manutenção de praticamente todo o patrimônio simbólico sandinista com a FSLN $^{37}$. Apesar desta constatação acima, nos interessa notar a liderança de Ramírez na criação e no rumo proposto ao partido.

Como afirmado, defendemos a hipótese de Ramírez como interlocutor da cultura política sandinista e de uma tendência e tradição associada à ela, baseada nos atributos éticos de Sandino e em sua valoração histórica. Na análise das culturas políticas, as esferas de socialização são elementos importantes na fundamentação das mesmas, e nesse ponto podemos incluir os partidos políticos. Tomando como premissa a ideia da inércia do político, existindo uma capacidade dos partidos de perdurar e originar uma tradição, Berstein $^{38}$ apontou que a formação ideológica dos partidos políticos pode se dar sob a forma de uma cultura política difusa, se impondo aos membros de dita formação. Desse modo, as funções do partido político, segundo o mesmo Serge Berstein, são as de mediação e socialização política e seleção das elites políticas. Entende-se por socialização política o viés da cultura que portam. Ademais, caberia aos partidos estruturarem o eleitorado, dandolhes uma identidade política; além de organizar a sociedade segundo novas clivagens, a das ideologias.

\footnotetext{
35 Nayar López Castellanos, Nicaragua, los avatares de una democracia pactada, Managua, UCA Publicaciones, 2013, 31.

${ }^{36}$ Em suas primeiras eleições em 1996, por exemplo, tendo Ramírez como candidato presidencial, obteve apenas $0,44 \%$ dos votos, menos de 8.000 eleitores. Também derrotado, Daniel Ortega, por sua vez, conseguiu $37,83 \%$, quase 665.000 votos.

${ }^{37}$ López Castellanos, op. cit.; Martí i Puig, op. cit.

38 Serge Berstein, “Os Partidos”, René Rémond (org), Por uma história política, Rio de Janeiro, Editora UFRJ/FGV, 1996.
} 
Em homenagem ao nascimento de Sandino, o MRS foi fundado em 21 de maio de 1995. Nessa mesma data foram aprovados seu estatuto, programa e regulamentos. As contradições sobre a política e atuação da FSLN foram retratadas principalmente em relação à democracia interna, às lutas político-sociais e às reformas constitucionais, condenando a inclinação centralizadora e autoritária de Daniel Ortega e seu grupo. O programa aprovado em dito marco fundacional é expressivo na captação do viés ético proposto, em consonância com a cultura política sandinista trabalhada por Ramírez:

Nicaragua vive una profunda crisis política, económica y social, pero que es sobre todo una crisis moral. El país parece haber perdido sus esperanzas y su visión de futuro, y al tiempo que regresan viejas formas de dominio y opresión, prosperan el egoísmo, la insensibilidad ante la miseria de las mayorías, la ausencia de solidaridad social, la ambición por el dinero fácil, la doble moral, la corrupción escandalosa, los negocios ilícitos, el culto al consumo, y la depredación de las riquezas naturales. [...] Es necesario romper para siempre con los esquemas autoritarios de poder, y colocar al ser humano como el centro de la historia, en una sociedad que recupere y promueva los valores fundamentales de solidaridad, desprendimiento y fraternidad. [...] Es así que nosotros, hombres y mujeres libres, en uso de nuestros derechos ciudadanos, y en el centenario del nacimiento de Sandino, hemos decidido constituirnos en partido político de inspiración social y democrática $[\ldots]^{39}$.

Tais quais as passagens de escritos e discursos de Ramírez expostos nas páginas anteriores, a preocupação com os aspectos éticos, morais e humanos é fulcral na estruturação do MRS. Nesse ponto de vista, a defesa de princípios de justiça social, democracia plenamente igualitária, soberania nacional, transparência e honestidade nas decisões políticas pode ser compreendida como uma tentativa de restaurar a postura ética do sandinismo enquanto cultura política, em contraposição às obsessões pessoais pelo poder conduzidas por outros setores oriundos da FSLN.

Os estatutos do MRS - aprovados em 1995 e posteriormente reformados reiteravam a atenção aos traços morais, além de associá-los à influência direta de Sandino:

Nos inspiran la gesta y los ideales de Sandino, nuestro héroe nacional, y hacemos nuestro el legado de las mujeres y hombres que, con sus obras, su vida y sus luchas han engrandecido la Patria, han defendido su soberanía y su decoro, y han elevado al pueblo a lo largo de nuestra historia. Rescatar su ejemplo y sus virtudes más allá de sus filiaciones políticas, será propósito de nuestro Partido ${ }^{40}$.

Por conseguinte, tendo Ramírez como líder, membro fundador e principal referência, o MRS atuou como um dos pilares da estabilização e difusão de uma tradição da cultura política sandinista aqui abordada. Sob a leitura política, o surgimento do MRS e das

\footnotetext{
39 Movimiento Renovador Sandinista, Principios y programa aprobados por la Convención Constitutiva, Managua, [s.n.], 1995, 02. O destaque é nosso.

${ }^{40}$ Movimiento Renovador Sandinista, Estatutos MRS, Managua, [s.n.], 2012, Arto. 3, 03.
} 
divisões transparece na FSLN o gradual abandono das posições revolucionárias para priorizar uma prática política pragmática encaminhada à proteção do poder do partido dentro das então novas condições irrompidas com a transição ${ }^{41}$.

Os posicionamentos de Ramírez nesse período ressaltavam que o sandinismo como ideal nacional aglutinador sempre esteve presente, especialmente nos setores populares que sonharam com uma melhora substancial em suas condições de vida. O problema seria o "desvirtuamento" daqueles que detinham as esferas de poder e que focaram mais nos princípios político-partidários do que em valores básicos de uma incipiente democracia. Para Ramírez, a rigidez de pensamento dos dirigentes políticos se sobrepôs aos ideais morais recuperados de Sandino: "En esto, el sandinismo, como prédica y como sentimiento, tuvo una calidad humanista, que al final debía terminar chocando con el rígido modelo propuesto que partía de la concepción de vanguardia dueña de la razón histórica total y que era, por lo tanto, antidemocrática ${ }^{42}$ ".

\section{Considerações finais}

A etapa de renovação era percebida por Ramírez como necessária para manter o sandinismo como força popular, nacional e democrática. Pouco antes de se desligar da FSLN, o intelectual afirmou: "El desafío es demostrar que existe un sandinismo nuevo, viable, un sandinismo que sea alternativa de poder ${ }^{43}$ ". Porém, como minoria dentro de um partido que se considerava rigidamente preso a tradições revolucionárias, sua posição foi suplantada por posturas ortodoxas de outros membros que insistiam na manutenção da mesma dinâmica partidária da década anterior, sem reconhecer erros ou atitudes equivocadas. Para Erick Aguirre ${ }^{44}$, as separações e saídas de membros e grupos estavam associadas a não aceitação pela cúpula dirigente da posição da FSLN no novo cenário democrático e igualmente da importância dessa colocação para o aprimoramento político do país.

Estrategicamente, o MRS pretendia manter vivo o sandinismo enquanto gerador de consenso e unidade nacional, buscando resguardar os ideais de Sandino como a mais alta expressão de patriotismo nicaraguense. Com atuação mais destacada em meados dos anos 1990, nos primeiros anos como agrupação partidária, a prática política do MRS se direcionava ao estabelecimento de um Estado mais justo e de uma sociedade mais democrática, sempre reivindicando os princípios sandinistas como orientação.

As eleições de 1996, com Ramírez como candidato presidencial, revelou-se uma frustração para o grupo, tendo como consequência um natural enfraquecimento em seu

\footnotetext{
${ }^{41}$ Andrés Pérez-Baltodano, Entre el Estado Conquistador y el Estado Nación: providencialismo, pensamiento político y estructuras de poder en el desarrollo histórico de Nicaragua, Managua, Instituto de Historia de Nicaragua y Centroamérica - Universidad Centroamericana, 2003, 672.

${ }^{42}$ Ramírez, op. cit., 2000.

43 Sergio Ramírez apud Erick Aguirre, La espuma sucia del río: sandinismo y transición política en Nicaragua, Managua, CIRA, 2001, 75.

${ }^{44}$ Ibid., 76.
} 
vigor e na disposição de seus membros, principalmente em Ramírez. Distante das esferas de poder e progressivamente dos palcos políticos, ele retornaria ao ofício de escritor como atividade elementar, mas sem abandonar suas referências e a cultura política sandinista em que estava inserido e promovia. Acerca desse plano, em uma visão em perspectiva, indicou Ramírez:

Mi ruptura con la cúpula del FSLN tuvo antes que nada motivos éticos. No podría explicarlo de otra manera. Los presupuestos fundadores de la revolución habían sido rotos y la lucha popular había pasado a ser un concepto retórico detrás del que se ocultaban ya los negocios y los vicios de la política tradicional, como la historia ha seguido demostrando con creces. La defensa de cuotas de poder, para sostenerse de alguna manera en el poder, había abierto ya grandes boquetes a la credibilidad del sandinismo oficial, que empezaba a hacer agua sin remedio, y que terminó de naufragar en el pacto con el Partido Liberal. Y los grandes presupuestos morales del inicio, fraternidad, solidaridad, entrega, desprendimiento, humildad, rechazo a la acumulación de bienes materiales, habían sido malversados. [...] Ahora que me he retirado definitivamente de la política activa, y no tengo ninguna pretensión de regresar a ella porque he regresado para siempre a mi oficio de escritor, puedo aspirar quizás a que mis juicios sean más serenos. Un escritor, sin embargo, que no puede cerrar la ventana frente a la que escribe y negarse, por lo tanto, la visión de su país, por amarga y desolada que ésta sea ${ }^{45}$.

A saída de Ramírez da FSLN, a fundação do MRS e o decorrente distanciamento da política institucionalizada e partidária foram momentos de certificação e refiguração de uma vertente vinculada à cultura política sandinista. Ao redobrar a atenção aos valores morais de Sandino e na vigência dos mesmos, Ramírez promovia uma orientação de condutas, permitindo uma forma de identidade de indivíduos que se aproximavam do ponto de vista divulgado por ele, favorecendo o reconhecimento tanto de uma tendência como o de uma ampla cultura política.

$\mathrm{O}$ afastamento dos partidos políticos (primeiro da FSLN e depois do MRS) pode ser entendido como modificação nas estratégias de socialização de dita cultura política: passava-se de esferas tradicionais como os partidos para a percepção da literatura como instrumento de difusão. Ou seja, aplicava-se a narração como artifício de imaginação vinculado a realidades concretas. Por meio de suas "mentiras verdadeiras", de metáforas do poder e das "anormalidades da história", Ramírez colocava em prática a perspectiva da literatura ficcionalizando a história e se nutrindo do que a "história oficial" deixou de contar $^{46}$.

Desse modo, a cultura política sandinista se entrelaçava em uma projeção coletiva buscada pelas obras de Ramírez; uma promoção da cotidianidade da história através do uso literário como fonte de informação. Abre-se espaço, então, para uma possível discussão

\footnotetext{
${ }^{45}$ Ramírez, op. cit., 2000. O destaque é nosso.

46 TUVESSON, Cecilia. Novelas nicaragüenses de contenido político. Un estudio de obras literarias de Gioconda Belli y Sergio Ramírez. Tese em Spanish Studies - Lunds Universitet. Lund, Suécia, 2012. p. 39.
} 
entre o fim do projeto político de uma organização que se autointitulava sandinista (FSLN) e seus legados na sociedade nicaraguense. Ou seja, a interpretação de que a derrota eleitoral não significou o fim do sandinismo enquanto força aglutinadora. Para além da relevância e centralidade de Sergio Ramírez aqui trabalhada, dito exercício analítico mostra-se relevante no estudo do sandinismo como tradição política, e mais especificamente, da cultura política e suas tradições presentes ao seu redor. Tal temática ainda foi pouco abordada e carece de pesquisas se levarmos em consideração a magnitude da influência sandinista na Nicarágua. Nesse sentido, buscamos contribuir em meio à tal dimensão. Ademais, e por fim, mesmo que na América Central a categoria intelectual não atue como parte de uma classe única com interesses concretos, tampouco constitua um grupo bem definido, a análise da ação de um intelectual que teve um rol político e cultural protagônico, como Sergio Ramírez, mostra-se relevante para compreendermos os caminhos trilhados por um país tão pouco estudado, porém consideravelmente significativo nas transformações políticas do istmo e da região latino-americana.

\section{Referências}

Aguirre, Erick, La espuma sucia del río: sandinismo y transición política en Nicaragua, Managua, CIRA, 2001.

Baracco, Luciano, Nicaragua: the imagining of a nation. From Nineteenth-century Liberals to Twentieth-century Sandinistas, New York, Algora Publishing, 2005.

Berstein, Serge, "Os Partidos”, Rémond, René (org), Por uma história política, Rio de Janeiro, Editora UFRJ/FGV, 1996.

Berstein, Serge, "A cultura política", Rioux, Jean-Pierre; Sirinelli, Jean-François, Para uma História Cultural, Lisboa, Estampa, 1998.

Fonseca, Carlos, "Viva Sandino", Baltodano, Mónica; Stedile, João Pedro (orgs.), Sandino: vida e obra, São Paulo, Expressão Popular, 2008.

López Castellanos, Nayar, Nicaragua, los avatares de una democracia pactada, Managua, UCA Publicaciones, 2013.

Martí i Puig, Salvador, "Mutaciones orgánicas, adaptación y desinstitucionalización partidaria: el caso del Frente Sandinista de Liberación Nacional (FSLN), 1980-2006", Revista de Estudios Políticos (nueva época), n. 143, 2009.

Moro, Diana Irma, La narrativa de Sergio Ramírez y las significaciones de la figura de Rubén Darío en la constitución de la literatura nicaragüense, Tese de Doutorado em Letras, Universidad Nacional de La Plata, Facultad de Humanidades y Ciencias de la Educación, 2013.

Moro, Diana Irma, "Sergio Ramírez: ensayo y autofiguración”, Revista Pilquen, Sección Ciencias Sociales, XVI, 17:01, 2014. 
Movimiento Renovador Sandinista, Principios y programa aprobados por la Convención Constitutiva, Managua, [s.n.], 1995.

Movimiento Renovador Sandinista, Estatutos MRS, Managua, [s.n.], 2012.

Pérez-Baltodano, Andrés, Entre el Estado Conquistador y el Estado Nación: providencialismo, pensamiento político y estructuras de poder en el desarrollo histórico de Nicaragua, Managua, Instituto de Historia de Nicaragua y Centroamérica - Universidad Centroamericana, 2003.

Ramírez, Sergio, "El ideario político-social de Sandino y el sandinismo. Análisis histórico-social del movimiento sandinista desde el origen hasta la maduración", Encuentro: Revista Académica de la Universidad Centroamericana, n. 15, 1980.

Ramírez, Sergio, "Vigencia del pensamiento sandinista". Conferencia pronunciada por el doctor Sergio Ramírez Mercado, miembro de la Junta de Gobierno de Reconstrucción Nacional, en el auditorio del diario Barricada, Managua, 3 de febrero de 1983, Instituto de Estudio del Sandinismo, El sandinismo: documentos básicos, Managua, Editorial Nueva Nicaragua, 1983.

Ramírez, Sergio, El pensamiento vivo de Sandino, Managua, Editorial Nueva Nicaragua, 1984.

Ramírez, Sergio, "El muchacho de Niquinohomo", Ramírez, Sergio, El pensamiento vivo de Sandino, Managua, Editorial Nueva Nicaragua, Tomo 1, 1984.

Ramírez, Sergio, El alba de oro: la historia viva de Nicaragua, México, D.F., Siglo Veintiuno Editores, 1985.

Ramírez, Sergio, "Un sandinismo en el que creer", Ramírez, Sergio, Oficios compartidos. Un sandinismo en el que creer, Poitiers, França, Centre de Recherches Latino-Américaines-Archivos, 2000.

Ramírez, Sergio, "Sandino, classe e ideologia", Baltodano, Mónica; Stedile, João Pedro (orgs.), Sandino: vida e obra, São Paulo, Expressão Popular, 2008.

Tuvesson, Cecilia, Novelas nicaragüenses de contenido político. Un estudio de obras literarias de Gioconda Belli y Sergio Ramírez, Tese em Spanish Studies - Lunds Universitet, Lund, Suécia, 2012. 